\title{
Identifying the effectiveness of e-learning platforms among students using Eye-Tracking technology
}

Chivu, Raluca-Giorgiana ${ }^{\text {a }}$; Turlacu, Luiza-Maria ${ }^{\text {b }}$; Stoica, Ivona ${ }^{\text {c }}$; Radu, AndraVictoria $^{\text {d }}$

${ }^{\mathrm{ab}}$ Department of Marketing, The Bucharest University of Economic Studies' Romania, c'Dimitrie Cantemir" Christian University, 'University of Medicine and Pharmacy "Carol Davila"

\begin{abstract}
The emergence of computers has led to a rapid evolution of the learning environment. In recent decades, new information and communication technology tools have contributed to major changes in learning. In this way, new forms of learning have emerged, such as learning in the virtual environment (e-learning). To support online education, it was necessary to develop a whole industry. Today there are a lot of products and services on the market from which you can choose the optimal solution. In this article were analyzed two of the elearning platforms within prestigious universities in Romania, in order to identify students' opinions about their existence, the degree of utility and usability they feel, and the possibilities for their improvement for a more good absorption among beneficiary students. The results have shown that elearning platforms are seen as a plus for the student, but there are still possibilities for improvement to catch up on the technologically advanced level.
\end{abstract}

Keywords: E-learning; eye-tracking; higher education. 


\section{About E-learning}

There are many answers to the question "What is eLearning?" Some common answers would be: Internet, network or CD-ROM education; electronic transfer of skills and knowledge, a distributed learning component that includes digital content and is experienced through an kind of interface created with the latest technology available through the Internet. With the increase in Internet coverage and the evolution of gadgets, the education system has adapted to new media, helping to attract students and young people to the Internet by creating and delivering e-learning platforms, recognized as the online basis of courses taught in the classroom. About eLearning we can say that it has its starting point in the desire for effective communication between student and teacher. The basics of eLearning reflecting and summing up both the principles of teaching and teaching (Hubackova, 2014). In other words, through eLearning in a broad sense, we can understand a distance learning teaching process achieved through computer and communication technologies that allow the elimination of geo-spatial boundaries between teacher and student. The development of eLearning is closely related to the development and improvement of technology, increasing the usability and accessibility of computers or other electronic tools that can easily access learning platforms online (Hubackova, 2014).

Specialists believe that with the proper use of eLearning technologies or learning through the online environment, the learning environment of students can be enhanced, giving them the chance to gather information when they feel they are ready or when they feel it is needed, without being suppressed under the space and time limit, as is the case with the classical teaching process (Lam, et al., 2014). Also, another advantage of using electronic forms of teaching is the degree of permissiveness of the author or the creator of the course who can adapt teaching methods so as to best fit the learning style adopted by the student, precisely because in the classical teaching process learning, this is known to be one of the main obstacles to the transmission of information (Hubackova, Klimova, 2013).

On the other hand, however, within the techniques and tools used, the teacher / author has a lower control over the degree of access, or use of the information provided by the students. In this manner, the only possible assessment of the efficiency of using eLearning techniques is to undergo a form of examination of the beneficiary students. However, even under these conditions, the use of e-learning methods and platforms has become a trend especially in higher education institutions, where there is a common interest in their use, both on the part of teachers who are easier to communicate with the course holders or other organizational or administrative information, as well as for students, who are easily able to access whenever they consider necessary course support or information received. Another essential utility is found in non-frequent or distance education, where it is almost impossible to have direct communication between a professor and a student, which is why the eLearning platforms represent a real advantage, especially if most students think they 
have a medium-high experience of using a computer or laptop, or other gadgets through which they can access e-learning resources and / or e-learning platforms (Popovici and Mironov, 2015).

\section{Eye-tracking, modern method of research}

In terms that are easy to explain, Eye-Tracking is the technique of measuring eye activity. What are we looking at? Where do we look? What are we ignoring? The reason we blink? How does the pupil look at different stimuli? All of these answers can be found through this neuromarketing tool. Data provided by Eye-Tracking can accurately provide information about where consumers are interested in an image (Fen, et al., 2018)

According to Jacob and Karn (2003, p.574), computer-based studies of eye movements date back more than 100 years. To observe the movements, the initial methods of determining the ocular position were quite invasive, invoking a direct contact between the mechanical instrument and the cornea. In 1901, the first non-invasive method of observing eye movements through the corneal reflection was developed, but at that time it was possible only for horizontal movements and without the subject being allowed to move his head. It was not until 1930 that scientists began to apply the methods until then, developing them and managing to perceive eye movements in all directions at the time of reading. In 1948, Hartridge and Thompson created the first eye-observation device attached to the head of the subject. Of course, with the passage of time things have evolved more and more, reaching today, with a gadget that we can see where the subject looks, what attracts more attention, why, s.a.m.

In order to determine all of these indicators, a device called eye tracker is required. "Eye tracker is a piece of hardware that recognizes eye movements at the computer screen, or on an object, or the environment in general" (Bojko, 2013, p.6). There are several types of eye trackers: some are attached to a pair of glasses or a special hat that bears the subject of the research, others are attached to computer monitors. Their mechanism of operation is based on a transparent, infrared light beam, pointing to the human face, which recognizes two standard elements: reflection of the retinal light, which contributes to the centering of the pupil and the reflection of the light in the cornea.

\section{Research}

Research is based on identifying the degree of accessibility of elearning platforms among students through Eye-Tracking tools. Thus, by displaying images, screenshots from various elearning platforms, and through the device, I have an observer that was the most attractive area for the student, and how intensely or quickly they read the information in the picture. 
Basically, to obtain additional information, an experimental "Before-After Without Control Group" experiment was used, in which, the previously measured variable was the level of notoriety and usability of the Elearning platforms, the experimental treatment consisted of displaying E-learning platforms for people in the target group, after which an interview guide was made as a measurement after, from which we tried to highlight the differences.

\subsection{The study}

The images used were taken from the two e-learning platforms of prestigious universities in Romania, namely the Bucharest University of Economic Studies and the Polytechnic University of Bucharest, to perform both a comparative analysis of the two possibilities of the user interface, and to identify what points of interest the student is and what improvements or recommendations he / she would bring to increase traffic on the platforms. Basically, to obtain additional information, an experimental "Before-After Without Control Group" experiment was used, in which, the previously measured variable was the level of notoriety and usability of the Elearning platforms, the experimental treatment consisted of displaying E-learning platforms for people in the target group, after which an interview guide was made as a measurement after, from which we tried to highlight the differences.

\subsection{Methodology of research}

The study was led by the formation of a group of participants, a student, composed of 35 persons, an interview guide on the knowledge, awareness, interest, attitude and usage of the eLearning platforms was applied to the charity, to be given an experimental treatment (pictures with the interfaces of the two eLearning platforms analyzed), where responses, attention levels and eye movements were observed with the Eye-Tracking device.

\subsection{Developing the interview guides}

The interview applied before the experimental treatment made reference to the degree of use and the reputation of the eLearning platforms as well as to the students' attitude towards them, while the interview applied after viewing the images was more practical, referring more to the subjective opinion towards the eLearning platforms analyzed in the research.

\subsection{Interpretation of results}

In the interview before the platforms, the conclusions obtained from the respondents' answers showed that "most of the interviewed students stated that eLearning platforms are a great addition to their evolution in the university environment by allowing them to access and read the materials curriculum at any time, and anywhere, and that they no longer feel connected with this obligatory physics during the classroom, managing to combine studies with a job. 
We were also interested at what time of day the students use the eLearning platforms, and the responses were grouped according to Fig.1, the students motivating the choices made in terms of the available time allocated for the hours spent at work or other daily activities.

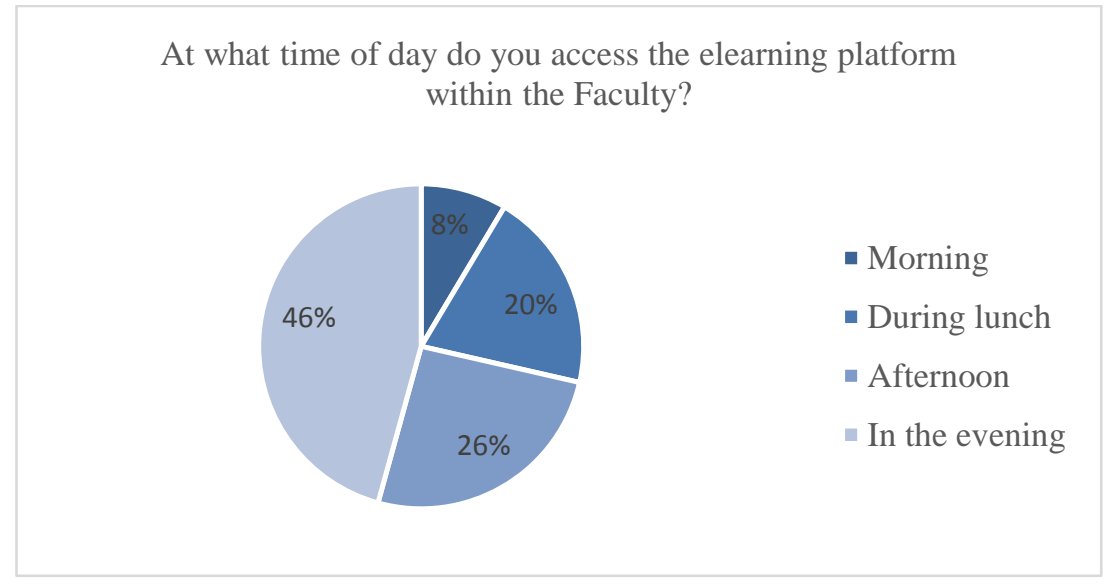

Fig.1. The moment when elearning platforms are accessed. Source: made by the author in the research

Another question relevant to this research was the question of how often students access the elearning platforms of the faculties, the results showing according to Fig. 2, the participating students motivating that they use the elearning platform more often during the exams during the semester.

How often do you access the elearning platform within the faculty?

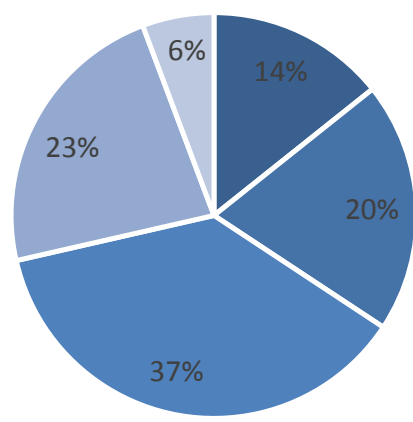

- Several times a day

- Once a day

- 2-3 times a week

-2-3 times a month

- Rarely once a month

Fig.2. Frequency of access to elearning platforms. Source: made by the author in the research

Subsequently, the participants showed the pictures with the two platforms, and before interpreting the results obtained during the interview after this experimental treatment, we discussed the ways of observing and focusing on the platforms, as follows: 


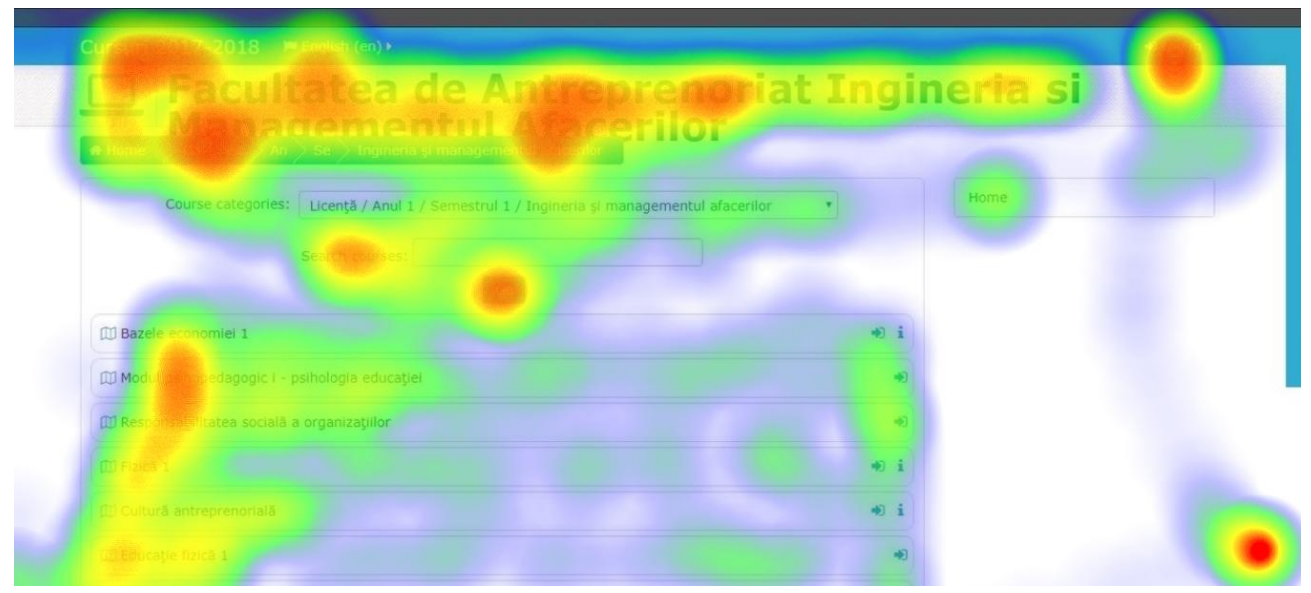

Fig. 3. Heat map of the eLearning platform ASE Bucharest. Source: made by the author in the research

In the case of the elearning platform at the Bucharest Academy of Economic Studies, we can see from the heat-map analysis that the students' attention was focused more on the menu on the left and on the course names, while still looking at the edges of the screen in search of additional information or instructions for use.

As mentioned, the eye-tracking device measures and monitors both eye movements, indicating the locations and areas in which the participant looks, as well as the intensity and duration of staying on a visual element. In the attached picture, we can see that the more pronounced red shades highlight the points of interest for the participants, such as the platform's use menu and course names.

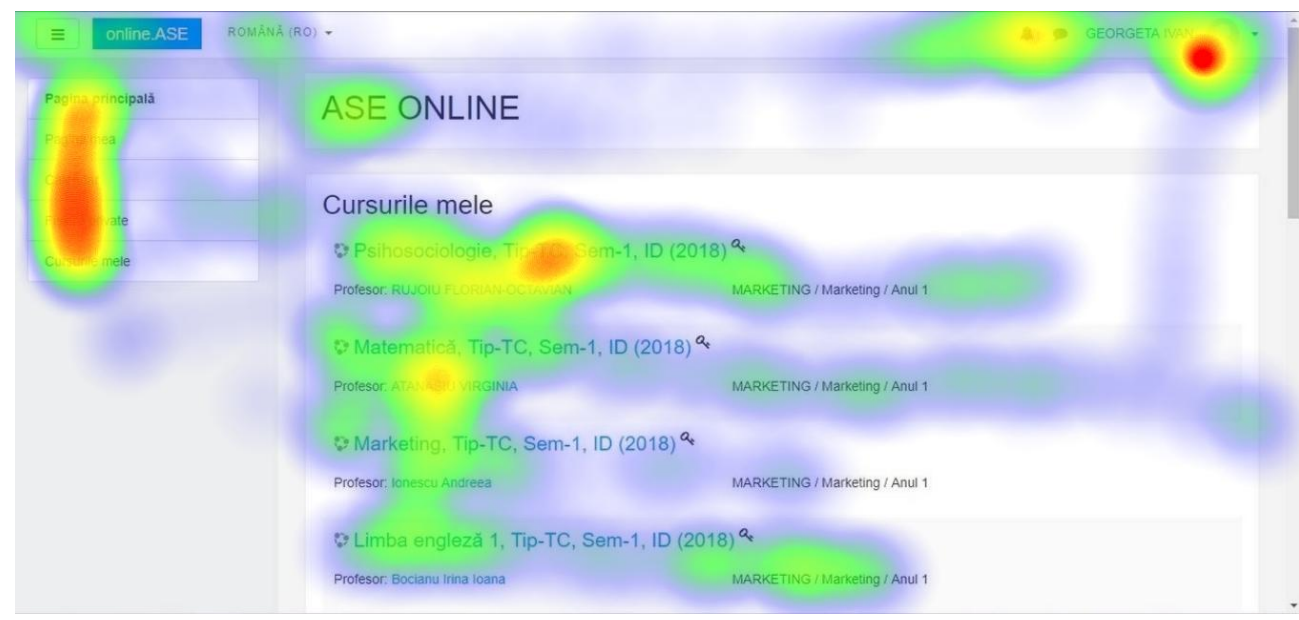

Fig. 4. Heat map of the e-learning platform Politehnica Bucuresti. Source: made by the author in the research 
In the case of the e-learning platform at the Politehnica University of Bucharest, it is highlighted by the heat map that the students attended more attention to the name of the faculty. Subsequently, when asked why they thought they paid more attention to that area on the web page, most of the papers were related to the font and dimensions used for editing, and the absence of a menu visible directly on the homepage platform. Also, in the case of the same image, the participating students looked both at the course names and in the free spaces until the logs, search and home buttons were identified.

Finally, the participating students were asked what improvements they thought could be brought to eLearning platforms, and their responses indicated a more user-friendly interface that would not look outdated, and maybe a better organization of courses and seminars, grouped by years study, disciplines, etc.

\section{Conclusions}

In the research, we have seen that elearning platforms are useful and effective tools for higher education, with a high degree of notoriety. On the basis of the experiment I have obtained information on the degree of use of such platforms, the frequency of use and the possible improvements that could be made to them. Through the Eye-Tracking measurement tool, we have obtained relevant insights into the positioning of menu items within elearning platforms to make them more user-friendly and user-friendly, as well as on the elements and spaces on the web page students and / or users pay attention. Thus, we can easily identify where we can place a general interest announcement on platforms to be seen by users.

\section{References}

Bojko, A., (2013). Eye Tracking the user experience- A Practical Guide to Research, New York: Rosenfeld.

Fen, X., Liangchan, P., Gao, L. and Xieping, G., (2018). Salient object detection based on eye tracking data, Signal Processing, 144(392-397).

Hubackova, S., (2014). Pedagogical Foundation of Elearning, Procedia - Social and Behavioral Sciences, 131(May)(24-28).

Hubackova, S., (2015). History And Perspectives Of Elearning, Procedia - Social and Behavioral Sciences, 191(1187 - 1190).

Hubackova, S., and Klimova, B.F., (2013). Pedagogical Aspects of eLearning. Language On-line Course and Issues of Learning Styles, Procedia - Social and Behavioral Sciences, 93(1095 - 1098).

Jacob, R.J.K. and Karn, K.S., (2003). Eye Tracking in Human-Computer Interaction and Usability Research: Ready to Deliver the Promises, Mind, 2.3 :4. 
Lam, P., McNaught, C., Lee, J., and Chan, M., (2014). Disciplinary difference in students' use of technology, experience in using eLearning strategies and perceptions towards eLearning, Computers \& Education, 73(111-120).

Popovici, A., \& Mironov, C., (2015). Students' perception on using eLearning technologies, Procedia - Social and Behavioral Sciences, 180(1514 - 1519). 